\title{
USING OF THE WAVE TECHNOLOGIES IN INTENSIFICATION PROCESSES OF HEAT AND MASS TRANSFER
}

Oleg Burdo

Department of processes, equipment and energy management Odessa National Academy of Food Technologies

112 Kanatna str., Odessa, Ukraine, 65039

Valentyna Bandura

Department of processes and equipment processing and food production named after Prof. P. S. Bernik

Vinnytsia National Agrarian University

3 Solniachna str., Vinnitsa, Ukraine, 21008

bandura_3@ukr.net

Aleksandr Zykov

Department of processes, equipment and energy management Odessa National Academy of Food Technologies

112 Kanatna str., Odessa, Ukraine, 65039

Igor Zozulyak

Department of processes and equipment processing and food production named after Prof. P. S. Bernik

Vinnytsia National Agrarian University

3 Solniachna str., Vinnitsa, Ukraine, 21008

Julia Levtrinskaya

Department of processes, equipment and energy management Odessa National Academy of Food Technologies

112 Kanatna str., Odessa, Ukraine, 65039

\section{Elena Marenchenko}

Department of processes, equipment and energy management Odessa National Academy of Food Technologies

112 Kanatna str., Odessa, Ukraine, 65039

\begin{abstract}
The advantages of wave technologies in comparison with traditional thermal technologies are considered. The aim of research is using of innovative wave technologies to intensify the processes of heat and mass transfer in the processes of dehydration and extraction, while reducing energy costs. A classification of the mechanisms of intensification of heat and mass transfer processes is proposed. Technical methods for intensifying heat and mass transfer during the processing of plant raw materials using technologies for targeted delivery of energy are developed. Samples of equipment are presented that implement technologies of directed energy action and innovative products obtained at these facilities. The results of experimental studies of drying in the microwave and infrared fields are shown.

Keywords: wave technologies, targeted energy delivery, microwave technologies, mass transfer intensification, extraction, dehydration, innovative food concentrates.
\end{abstract}

\section{Introduction}

The scarcity of resources, especially energy, is one of the key problems of our time. Even in prosperous countries, there is a shortage of energy resources [1]. Because of the shortage of energy 
carriers, there is a problem of food shortages, since the food industry is one of the most energy-intensive industries in developed countries [2].

In the production of food products, significant energy losses arise in the processes of concentrating the raw materials: drying, dehydration, thickening, etc. [3]. The methods of heat treatment products for the subsequent transfer of water into steam are the most common. With this approach, the influence of high temperatures on the product is unavoidable, which has a bad effect on quality and leads to energy losses. For the production of food concentrates, fruit and vegetable raw materials containing a large number of vitamin complexes, organic acids, natural pigments and other valuable substances are dehydrated [4]. Products of animal origin contain a large number of proteins required by the body [5]. The effect of high temperatures destroys most of these components, and the nutritional value of the product is significantly reduced. A similar situation occurs in the extraction processes, where high temperatures make it possible to intensify diffusion processes [6].

Traditional thermal technologies, despite their availability and prevalence in food production, have significant shortcomings, which can't be reconciled. High-temperature equipment, in the overwhelming majority, does not comply with the norms of environmental safety, energy-consuming and, to a considerable extent, worsens the quality of the finished product [7].

It is necessary to search for alternative approaches to the organization of dehydration and extraction processes using innovative solutions aimed at increasing energy efficiency and reducing the high-temperature impact on the product and increasing the environmental friendliness of production [8].

\section{Materials and Methods}

The scientific and technical method proposed in the work is the organization of the effect on the boundary layers in the processes of heat and mass transfer by means of external inertial fields. Such fields are created by special generators, and the technology of their application is called wave. Wave technologies (WT) are technologies of directed mechanical or selective electromagnetic action on elements of raw materials and biological objects. It is possible to organize a directed influence on both nanoscale objects, micro- and nanoscale structures of food raw materials [8].

Both in the first and in the second cases, the task of the selective energy effect is to control the fields, to add directions of the force effects of weak fields, to reduce the size of the diffusion boundary layer, to organize the flow from the micro- and nanocapillary structure, to form the composition of these flows, the direction of the force impacts on the shells of the cellular structure of microbiological objects, etc. $[9,10]$.

For food systems, reducing the amount of consumed energy will not only increase the energy efficiency of the process and reduce the cost of the product, but also reduce the level of thermal effects on the product. This will lead to the preservation of thermolabile and biologically active components of food raw materials. For example, food products and culinary products obtained by WT will fully meet the requirements of functional nutrition.

The task is finding the effective principles, approaches for local actions aimed at intensive, low-energy operations with food raw materials, and even with individual nanosize elements of this raw material. One of the ways in this direction is WT. The basis of WT is innovative mechanisms of organization of mass transfer processes (Fig. 1). The means of intensification are electromagnetic (EMF) and mechanical vibrational fields, which are generated by external sources. This makes it possible to influence the hydrodynamic situation, to control the formation of the hydrodynamic, thermal and diffusion boundary layers. As a result, it becomes possible to substantially intensify mass transfer processes.

There are new opportunities, due to the action of specific mechanisms, combined moving forces. The authors of the study [9] put forward two hypotheses about the reserves of energy efficiency of food technologies. According to the first, the combined effect of the wave vibrational field and the heat flux should contribute to thinning the diffusion boundary layer. This can contribute to the intensification of dehydration and drying processes. According to the second hypothesis, the use, when extracting and dehydrating raw materials, of targeted delivery of electromagnetic energy directly to polar liquid molecules in capillaries will allow initiating a powerful, specific hydro- 
dynamic flow. As a result, the intensity of mass transfer will increase significantly due to a sharp decrease in internal diffusion resistance, energy costs and duration of the process will decrease.

The justification of the formulated hypotheses in mathematical modeling is based on phenomenological principles. The methodological novelty of the work is the representation of a complex hydrodynamic and diffusion flux in the form of an effective mass-transfer coefficient. New numbers of similarity are derived on the basis of the "dimensionality analysis" method, which are called "wave similarity numbers". The classical similarity numbers are modified and the Reynolds, Peclet and Stanton wave numbers are obtained. These numbers take into account the specificity of the action of electromagnetic and vibrational fields.

Experimental studies have used the techniques generally accepted for heat and mass transfer [1]. Particular dependences of the influence of regime and constructive parameters on the intensity of mass transfer have been established [10]. The obtained bases of the experimental data are generalized in the form of criterial equations [11].

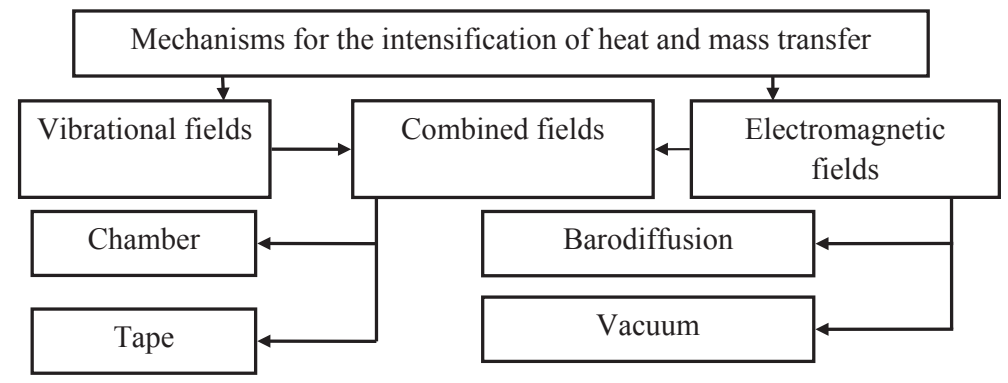

Fig. 1. Classification of the mechanisms of intensification of heat and mass transfer processes in food processing technologies

\section{Experimental procedures}

Based on the principles of targeted energy delivery, dehydration and extraction devices have been developed that use electromagnetic energy generators or combined effects on the product.

Tape microwave device (patent of Ukraine No. 28889) is designed for drying thermolabile raw materials and uses the above principles. The speed of the tape drive and the load capacity are regulated in a wide range $(0.007 . . .0 .025 \mathrm{~m} / \mathrm{s})$. The power of the emitters has a step-by-step control in the range $30 \ldots 100 \%$ of the nominal power of the magnetron. Stand testing of the device determined its high technical characteristics. Tape dryer has successive zones of microwave and infrared exposure to the product. Power control is the pulse modulation. Appearance of the device is shown in Fig. 2, a. Samples of dried fruits and vegetables were obtained using a tape dryer. The product well preserves color, aroma and taste. The obtained samples are shown in Fig. 2, b.

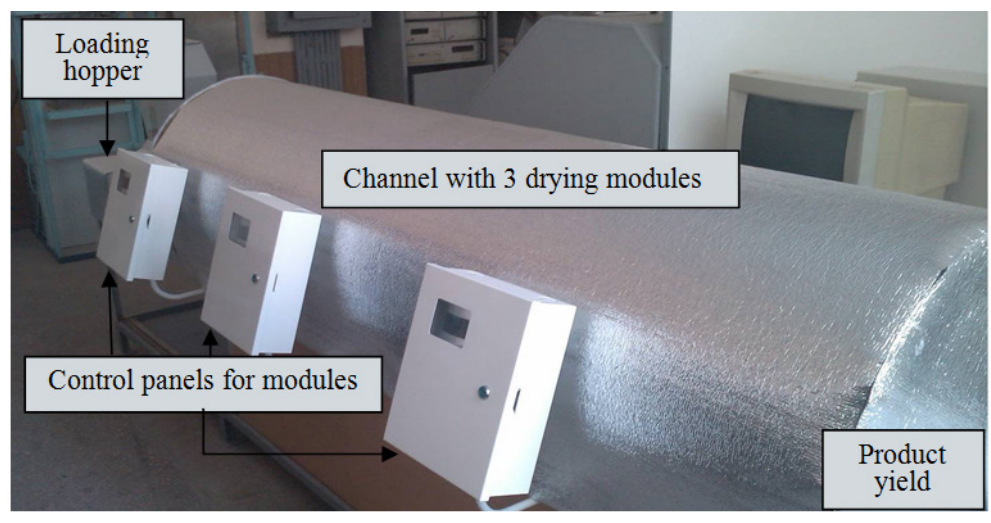

$a$

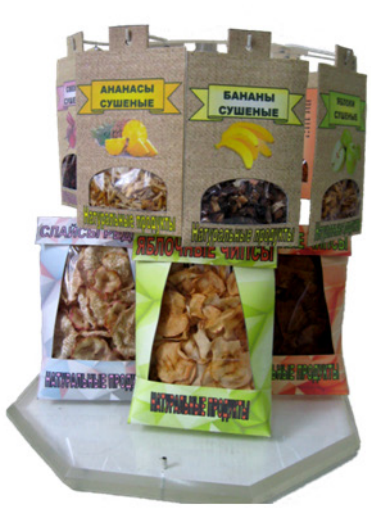

$b$

Fig. 2. Appearance of tape dryer with combined energy supply and samples of finished products 
The developed microwave drier (Fig. 2) differs and high intensity of mass transfer. Experimental data obtained during soybean drying (Fig. 3) showed that when the tape load is $\mathrm{m}=3,96 \mathrm{~kg} / \mathrm{m}^{2}$, the normative value of the final moisture content is reached in $35-40$ minutes.

Drying lines. Soybean. $\mathrm{m}=3,96 \mathrm{Kg} / \mathrm{m}^{2}$. Modules №1-3

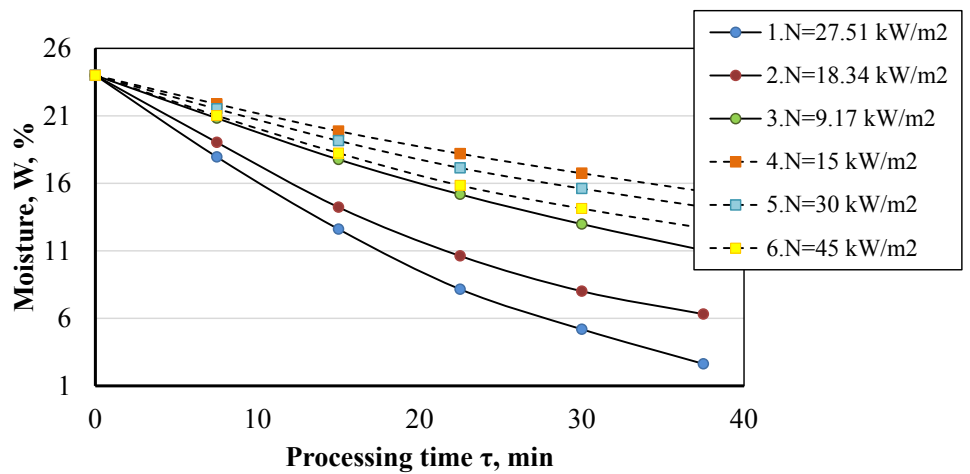

Fig. 3. Soybean drying lines in a tape microwave dryer

On the drying line (Fig. 3), the influence of the type of supplied energy and the specific power on the dehydration process is clearly observed. The use of three infrared emitters (IR-dotted lines) twice as much dries the soybeans to the required humidity level of $9 \%$. It has been experimentally established that microwave energy generators (straight lines) with different number of modules contribute to the removal of moisture almost equally, and for drying soybeans up to $9 \%$ it will take three times longer than using IR energy generators.

The process of moisture removal passed with a high intensity (Fig. 4).

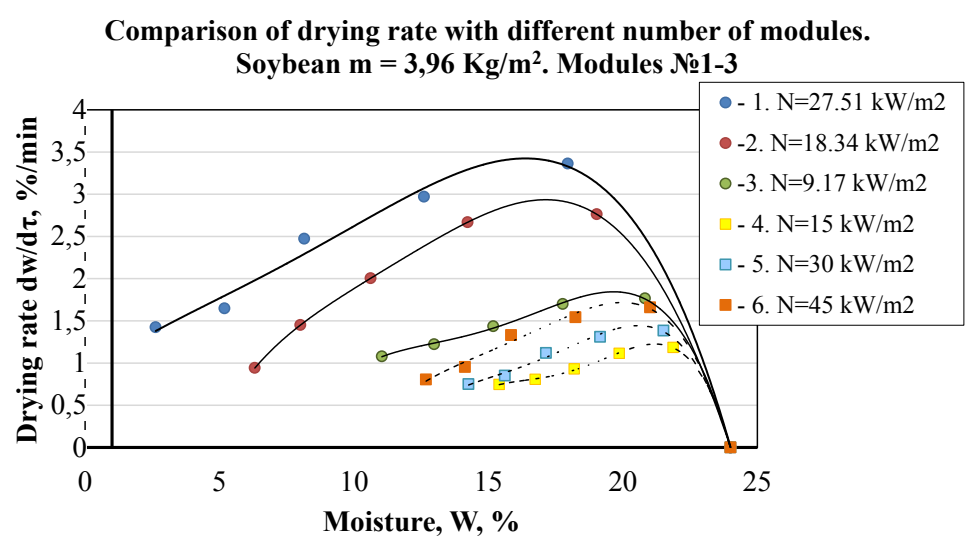

Fig. 4. Soybean drying rate lines with combined energy input

With an increase in the number of modules (Fig. 4), there are minor changes in the rate of soybean drying with the use of a microwave energy generator and quite significant changes in drying rate with the use of infrared emitters.

To obtain plant extracts of high concentration, a microwave countercurrent device, protected by patent of Ukraine No. 87503, has been developed. In the microwave extractor, a counterflow movement of the extractant and solid phase takes place, which makes it possible to intensify the process. The design characteristics of the extractor are given in Table 1, the external appearance - in Fig. 5. A concentrate of coffee extract with a solids content of $55 \%$ was obtained in the extractor. With traditional extraction methods, the concentration of solids in the extract does not exceed $18 \ldots 20 \%$ [8].

It is planned to introduce such extractors into production. Due to the fact that the extraction is carried out at atmospheric pressure - the design is simplified considerably, weight and size parameters of the equipment are reduced. Extraction is carried out at temperatures not higher than 
$100{ }^{\circ} \mathrm{C}$, which has a favorable effect on product quality. Microwave extractors are used to produce a concentrate of coffee extract, hips extracts, medicinal herbs (stevia, tarragon, etc.).

Table 1

Microwave extractor design characteristics

\begin{tabular}{ccccc}
\hline $\begin{array}{c}\text { Power } \\
\text { consumption, } \mathbf{k W}\end{array}$ & $\begin{array}{c}\text { Working } \\
\text { volume, } \mathbf{d m}^{\mathbf{3}}\end{array}$ & $\begin{array}{c}\text { Magnetrons } \\
\mathbf{( 0 , 9} \mathbf{k W}), \mathbf{p c s} .\end{array}$ & $\begin{array}{c}\text { Overall } \\
\text { dimensions (1/w/h), } \mathbf{m}\end{array}$ & $\begin{array}{c}\text { Productivity by } \\
\text { raw } \mathbf{m a t e r i a l , ~} \mathbf{k g} / \mathbf{h}\end{array}$ \\
\hline$\leq 7,3 \mathrm{~kW}$ & 180 & 5 & $0,52 / 0,68 / 2,05$ & $\leq 24$
\end{tabular}

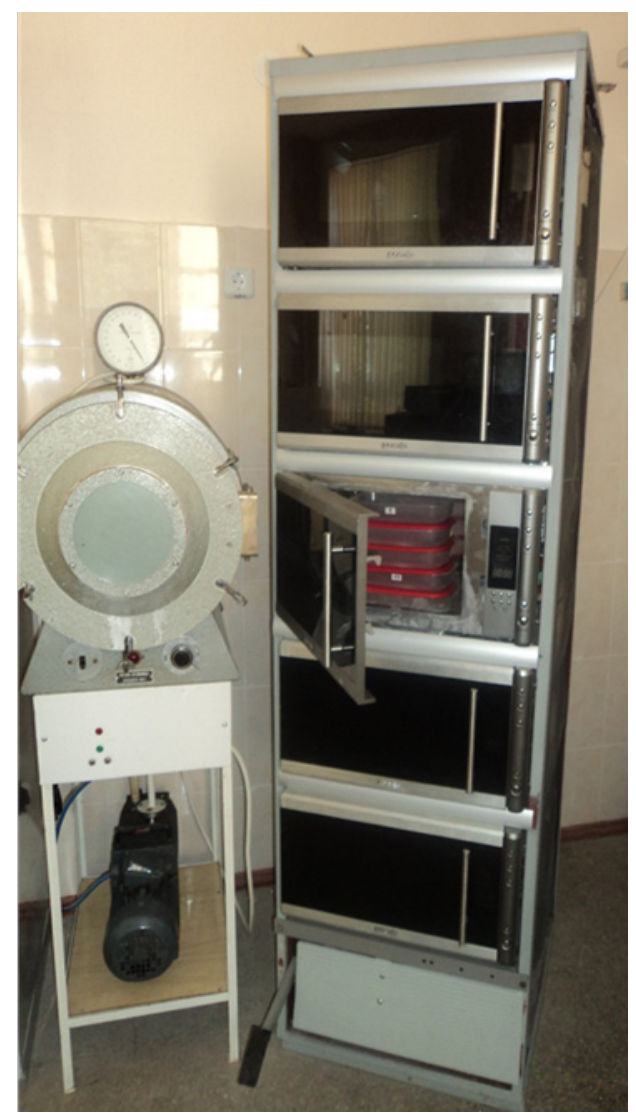

Fig. 5. Microwave extractor

\section{Results}

Drying in the microwave and infrared field allows to obtain a high quality product, due to the absence of high temperatures. When using wave generators, the rate of drying is significantly increased.

The use of wave technologies in the extraction process allows obtaining high-quality concentrates that retain useful properties due to the absence of high temperatures. The coffee concentrate obtained in the microwave extractor received a positive evaluation, which was noted in a number of acts of degustation.

The study of wave technologies and the principles of targeted energy delivery make it possible to create equipment with high efficiency indicators of mass transfer processes. The study of approaches to mathematical modeling of wave technologies will allow creating more efficient equipment, moving from a laboratory installation to an operating industrial model.

The use of wave technologies in the production of food products allows to reduce the temperature of the process, which gives a positive energy effect and allows to maintain the quality of the product. 


\section{Discussion of research results}

As a result of the studies with electromagnetic energy sources, the following facts are established:

- energy costs for removing moisture from raw materials are less than that of traditional drying equipment by $20 . .50 \%$;

- when extracted in the electromagnetic field of the microwave range, the output of the target components from raw materials is $4 . . .8 \%$ more than in traditional devices;

- when extracting in a microwave field in an extract, in addition to soluble components, insoluble substances also appear.

These facts confirm the hypotheses put forward by the authors about the possibility of targeted delivery of energy to individual elements of food raw materials. So, when drying, electromagnetic energy interacts with water molecules, dissipation of electromagnetic energy into heat occurs. As a result, a barodiffusion flow of a mixture of steam and moisture emerges from the capillaries of the raw material. It is a combination of diffusion and hydrodynamic flows. The more raw material (water) out in the form of a liquid phase, the lower the energy costs for dehydration.

When extracting, the barodiffusion flux from the volume of raw materials is carried out due to inertial forces and those substances that are absent in traditional extractive technologies. This explains the fact that the samples of the product obtained in the microwave extractor differ significantly for the better from the analogs.

At the same time, the full realization of the capabilities of devices that use the principles of directed energy action depends on a deep understanding of the complex and interrelated processes of interaction of electromagnetic fields and the structure of the product.

Studies aimed at an in-depth study of the effect of electromagnetic and vibration fields on dehydration and extraction processes are necessary for the effective development of equipment that implements innovative principles of directed energy action.

\section{Conclusions}

It is established that directed local energy action on nanoscale elements of food raw materials will allow developing innovative approaches to the organization of food technologies. Impulse actions are powerful means of initiating the appearance of nanokinetics. Combination of pulsed electromagnetic and vibrational fields allows significantly intensify the processes of heat and mass in the electromagnetic field.

The developed approaches to the mathematical description and evaluation of the influence of the field intensity on the intensity of mass exchange processes allow to find the principles of optimization of technological and design parameters, to formulate a methodology for designing innovative equipment.

Devices created with the use of wave technologies are protected by patents, it is planned to introduce microwave extractors and dryers in the food concentrates industry. Equipment created using the principles of targeted delivery of energy is distinguished by a reduced thermal effect, which positively affects the quality of food products and reduces energy costs. At the same time, the lack of practice of using such equipment in enterprises forms a barrier for the practical application of such equipment. It is necessary to determine the reliability reserves of such devices, to develop standard series for dryers and extractors, and to conduct additional production tests.

\section{References}

[1] Weibbach, D., Ruprecht, G., Huke, A., Czerski, K., Gottlieb, S., Hussein, A. (2013). Energy intensities, EROIs (energy returned on invested), and energy payback times of electricity generating power plants. Energy, 52, 210-221. doi: 10.1016/j.energy.2013.01.029

[2] Gromadzki, G., Konol, W. (2008). Energy game: Ukraine, Moldova and Belarus between the EU and Russia. Energy Security in Central and Eastern Europe. Prague, 19. 
[3] Aloqbi, A., Omar, U., Yousr, M., Grace, M., Lila, M. A., Howell, N. (2016). Antioxidant Activity of Pomegranate Juice and Punicalagin. Natural Science, 8 (6), 235-246. doi: 10.4236/ns.2016.86028

[4] Sorour, M. A. (2015). Optimization of Multiple Effect Evaporators Designed for Fruit Juice Concentrate. American Journal of Energy Engineering, 3 (2), 6. doi: 10.11648/j.ajee.s.2015030201.12

[5] Azoev, G. L., Degterev, D. A., Degtereva, E. A., Zobov, A. M.; Azoeva, G. L. (2011). Ryinok nano: ot nanotehnologiy-k nanoproduktam. Moscow: BYNOM, 320.

[6] Potapov, V. A., Yakushenko, E. N. (2013). Povyshenie energoeffektivnosti sushki vinogradnyih vyizhimok v massoobmennom module s konduktivnyim podvodom teplotyi. Naukovi pratsi Odeskoyi natsionalnoyi akademiyi harchovih tehnologiy, 43 (2), 179-184.

[7] Bernic, M., Raducan, M., Ciobanu, E. (2013). Drying Kinetics of Sunflower Seeds using Pulsed UHF Energy Intake. TEM Journal, 2 (4), 305-308.

[8] Burdo, O., Terziev, S., Levtrinskaya, Y. (2015). Energetika ekoindustrii pischevyih kontsentratov. Problemyi regionalnoy energetiki [Problemele energetici regionale], 3 (29), 112-118.

[9] Burdo, O. G. (2013). Pischevyie nanoenergotehnologii. Kherson: GRIN D.S., 294.

[10] Burdo, O. G., Terziev, S. G., Bandura, V. N. (2015). Printsipy napravlennogo energeticheskogo deystviya v pischevyih nanotehnologiyah. Problemyi regionalnoy energetiki, 1 (27), 79-85.

[11] Burdo, O. G., Zykov, A. V., Terziev, S. G., Ruzhitskaya, N. V. (2016). The Nanotechnological Innovation in Food Industry. International Journal of Engineering Research and Applications, $6(3), 144-150$. 